\title{
Comparison of the Effects of Er, Cr: YSGG Laser and Super-Saturated Citric Acid on the Debridement of Contaminated Implant Surfaces
}

\author{
Gholam Ali Gholamii $^{1+}$, Milad Karamlou ${ }^{1+}$, Reza Fekrazad ${ }^{2,3^{*}}$, Farzin Ghanavati ${ }^{1}$, Neda Hakimiha ${ }^{4}$, Georgios \\ Romanos $^{5}$ \\ ${ }^{1}$ Periodontology Department, Dental Faculty, Shahid Beheshti University of Medical Sciences, Tehran, Iran \\ ${ }^{2}$ Department of Periodontology, Dental Faculty - Laser research Center in Medical Sciences, AJA University of Medical \\ Sciences, Tehran, Iran \\ ${ }^{3}$ International Network for Photo Medicine and Photo Dynamic Therapy (INPMPDT), Universal Scientific Education and \\ Research Network (USERN), Tehran, Iran \\ ${ }^{4}$ Laser Research Center of Dentistry, Dentistry Research Institute, Tehran University of Medical Sciences, Tehran, Iran \\ ${ }^{5}$ Division of Periodontology, Eastman Institute for Oral Health, University of Rochester, Rochester, NY, USA
}

\begin{abstract}
*Correspondence to Reza Fekrazad

Address: Laser Research Center in Medical Sciences, AJA University of Medical Sciences, Tehran, Iran. Tel: +989123143138;

Email: rezafekrazad@gmail.com

${ }^{\dagger}$ These authors contributed equally to this work.
\end{abstract}

Published online 17 September 2018

\begin{abstract}
Introduction: Several techniques such as using citric acid, plastic curettes, ultrasonic devices, and lasers have been suggested for debridement of contaminated implant surfaces. This comparative investigation aimed to assess and compare the effects of Er, Cr: YSGG laser and super-saturated citric acid on the debridement of contaminated dental implant surfaces. Methods: In this in-vitro study, 12 contaminated failed implants were collected and randomly divided into 2 groups ( 6 in group A, and 6 in group B). Also, one implant was considered as the control. The implants were horizontally sectioned into coronal and apical portions and subsequently irradiated by Er, Cr: YSGG laser in coronal and citric acid in apical in group A and the opposite in group B. In order to evaluate the effect of water spray on the laser section, half the laser portion of the implants was irradiated using water, while the other half was irradiated without water with an irradiation time of 1 minute.

Results: Results revealed that calculus and plaque removal was greater in the laser part of both groups (with and without water) compared to citric acid parts and the correlation between calculus removal and surface roughness were statistically significant. Furthermore, the surface roughness in the citric acid parts was significantly higher than in laser parts. Water spray during irradiation had a very small influence on understudy factors.

Conclusion: Based on the results of this study, the Er, Cr: YSGG laser was more effective in calculus removal and caused less surface roughness compared with citric acid application.

Keywords: Contaminated implant; Er, Cr: YSGG laser; Citric acid.
\end{abstract}

\section{Introduction}

Dental implants are considered as a well-accepted treatment modality for tooth replacement with high success rates and expectable outcomes. ${ }^{1}$ Presently, there is a solid body of evidence to support the causative relationship between microbial contamination and pathogenesis of implant failures. Bacterial colonization on implant surfaces can irritate the peri-implant mucosa resulting in progressive destruction of the alveolar bone..$^{2-4}$ Up to now, several techniques, such as the use of citric acid, plastic curettes, ultrasonic devices, and lasers have been recommended for the treatment of peri-implant infections and debridement of implant surfaces. ${ }^{5,6}$
Lasers have the ability to present excellent tissue ablation and have high bactericidal effects; thus, laser application can open a new window in the treatment of failing implants. The Er,Cr:YSGG (erbium, chromium: yttrium, scandium, gallium, garnet) laser, operating at $2780 \mathrm{~nm}$, removes tissue through a hydrokinetic process in collaboration with water spray that inhibits temperature rise. ${ }^{7,8}$ The Er,Cr:YSGG laser is an FDAapproved laser device for osseous apical and periodontal surgeries, cleaning, shaping and enlarging root canals and decreasing total bacterial count. Moreover, it can increase bone-implant contact, accelerate healing and decrease postoperative pain. ${ }^{9,10}$ A study conducted at 
Temple University, Philadelphia, PA showed that within a confined space, laser was able to significantly reduce the bacterial count. ${ }^{11}$ A report by Crespi et al indicated that the use of erbium lasers can debride the root surface without damaging the walls. ${ }^{12}$

Citric acid is another increasingly popular agent for debridement and detoxification of implant surfaces. In the past, it was used for conditioning of root surfaces in regenerative osseous surgeries. Since the advent of implants, it has been used for detoxification of implant surfaces as well. However, extensive studies have not been carried out to assess the effect of citric acid on the surface of dental implants. ${ }^{6}$

The aim of the present in vitro study was to evaluate and compare the effect of Er,Cr:YSGG laser and supersaturated citric acid on the debridement and roughness of contaminated dental implants using scanning electron microscopy (SEM) analysis.

\section{Methods}

This in vitro study was conducted in Shahid Beheshti University of Medical Sciences in 2010. In this investigation 12 contaminated failed straight-walled tissue-level blasted with hydroxyapatite implants (due to severe peri-implantitis) with similar characteristic (Swiss Plus, Zimmer Dental Inc, USA) were collected and randomly divided into 2 groups (6 in group A, and 6 in group B). Also, one new implant was considered as the control (Swiss Plus, Zimmer Dental Inc, USA).

In group $A$, the threads of 6 implants were sectioned into coronal and apical portions and then the regions between coronal threads were irradiated using Er, Cr: YSGG laser (WaterLase, iPlus, Biolase, USA) operating at $2.5 \mathrm{~W}$ average power, a wavelength of $2780 \mathrm{~nm}, 25 \mathrm{~Hz}$, $100 \mathrm{~mJ}$ per pulse, $\mathrm{H}$ mode (pulse duration of $60 \mu \mathrm{s}$ ), 1600 W peak power with 600 micron tip, $1 \mathrm{~mm}$ distance and time irradiation of 2 minutes. To evaluate the effect of the water spray system, half of the coronal section was irradiated using 55\% water (WL) and 50\% air and the other half irradiated without water (L) with the same air percentage with time irradiation of 1 minute. Moreover, with one thread interval from the coronal threads, the apical threads were covered with super saturated citric acid 3\% (SSCA, Sigma-Aldrich, USA) for three minutes (citric acid was prepared in the Biology Laboratory of Shahid Beheshti University of Medical Sciences). After laser irradiation and citric acid application, all implants were washed with normal saline.

In group B, similar to group A the threads were sectioned into apical and coronal portions and the apical section was irradiated using Er,Cr:YSGG laser, operating at 2.5 W power, a wavelength of $2780 \mathrm{~nm}$ and $25 \mathrm{~Hz}$ with time duration of 2 minutes. Similar to group A, half of the apical section was irradiated using water and the other half irradiated without water by pulse duration of one minute. The coronal threads were covered with supersaturated citric acid 3\% for three minutes. A new implant fixture was used as the control and similar evaluations were done for it using SEM (scanning electron microscope, Philips XL 30, FEI Philips Electron Optics, The Netherlands). All specimens were evaluated in terms of intervals between threads using SEM at $15 \times, 25 \times, 100 \times, 250 \times, 1000 \times$ and $5000 \times$ magnifications.

Then the level of calculus removal from the implant surfaces, $0=$ no change, $1=$ barely (up to $25 \%$ ), $2=$ slight (25\%-50\%), 3=strong (50\%-75\%) and $4=$ complete removal (100\%) and change in surface roughness $(0=$ decreased, $1=$ no change, $2=$ increased $)$ and also the released amounts of aluminum $(\mathrm{Al})$, potassium $(\mathrm{P})$, titanium (Ti) and calcium $(\mathrm{Ca})$ were measured, with the aim of assessing the effect of decontamination methods (lasers and citric acid) on the surfaces of implants and changes in the surface chemical composition by means of SEM applying semi-quantification methods.

The collected data were entered into SPSS (version 16) software (IBM SPSS software, USA). Data were expressed as mean \pm standard deviation (SD). Non-parametric Friedman test was used to compare the differences between the three techniques. Non-parametric Wilcoxon signed-rank test was used to compare the 2 techniques. We also used Friedman and Wilcoxon signed-rank tests to measure the AL, P, Ti and Ca content on the surface of implants after treatment.

\section{Results}

We evaluated a total of 12 implants in 2 groups. According to the Friedman test, the difference between the three treatment techniques in terms of calculus removal was significant in both groups $(P=0.04$ for group $\mathrm{A}$ and $P=0.01$ for group B). Using Wilcoxon signed-rank test, the only significant difference in group A in terms of calculus removal was between supersaturated citric acid and water + laser $(P=0.03)$. The differences between WL and $\mathrm{L}(P=0.18)$ or between citric acid and $\mathrm{L}(P=0.12)$ were not statistically significant (Table 1 ).

In group $\mathrm{B}$, the differences between $\mathrm{WL}$ and $\mathrm{L}$ with acid citric were significant $(P=0.03$ and $P=0.04$, respectively) (Table 1); but the difference between WL and L was not statistically significant $(P=0.5)$ (Table 1$)$.

In group $\mathrm{A}, \mathrm{WL}$ and $\mathrm{L}$ decreased the surface roughness of implants, while acid citric increased the surface roughness (Table 2; Figure 1). In the group B, WL and $\mathrm{L}$ decreased the surface roughness but citric acid did not impact half of the implants. The difference between the three techniques in this respect was significant in both $\mathrm{A}$ and $\mathrm{B}$ groups ( $P=0.04$ and 0.03 , respectively).

In group $\mathrm{A}$, using Wilcoxon test, the difference between citric acid and $\mathrm{L}$ in changing surface roughness was significant $(P=0.05)$ but the differences between $\mathrm{L}$ and WL $(P=0.3)$ or citric acid and WL $(P=0.06)$ were not statistically significant.

In group $\mathrm{B}$, the difference between citric acid and $\mathrm{L}$ in 
Table 1. Comparison of Calculus Removal by 3 Techniques in 2 Groups

\begin{tabular}{|c|c|c|c|c|c|c|c|c|c|}
\hline \multirow{2}{*}{$\begin{array}{l}\text { Calculus } \\
\text { Removal }\end{array}$} & \multicolumn{3}{|c|}{$\begin{array}{l}\text { Group A } \\
\text { No. }(\%)\end{array}$} & \multicolumn{3}{|c|}{$\begin{array}{l}\text { Group B } \\
\text { No. }(\%)\end{array}$} & \multicolumn{3}{|c|}{$\begin{array}{c}\text { Total } \\
\text { No. }(\%)\end{array}$} \\
\hline & WL & $\mathbf{L}$ & Acid & WL & $\mathbf{L}$ & Acid & WL & $\mathbf{L}$ & Acid \\
\hline 0 & 0 & 0 & 0 & 0 & 0 & 1 (16.7) & 0 & 0 & $1(8.3)$ \\
\hline 1 & 0 & 1 (16.7) & $3(50)$ & 0 & 0 & $2(33.3)$ & 0 & $1(8.3 \%)$ & $5(41.7)$ \\
\hline 2 & $2(33.3)$ & 1 (16.7) & $2(33.3)$ & 1 (16.7) & 0 & $2(33.3)$ & $3(25)$ & $1(8.3)$ & $4(33.3)$ \\
\hline 3 & $2(33.3)$ & $4(66.7)$ & 1 (16.7) & $2(33.3)$ & $5(83.3)$ & $1(16.7)$ & $4(33.3)$ & $9(75)$ & $2(16.7)$ \\
\hline 4 & $2(33.3)$ & 0 & 0 & $3(50)$ & 1 (16.7) & 0 & 5 (41.7) & $1(8.3)$ & 0 \\
\hline Total & $6(100)$ & $6(100)$ & $6(100)$ & $6(100)$ & $6(100)$ & $6(100)$ & 12 (100) & 12 (100) & $12(100)$ \\
\hline
\end{tabular}

Abbreviations: WL, laser with water irrigation; L, laser without water irrigation.

Table 2. Comparison of Change in Surface Roughness by 3 Techniques in 2 Groups

\begin{tabular}{|c|c|c|c|c|c|c|c|c|c|}
\hline \multirow{2}{*}{$\begin{array}{l}\text { Surface } \\
\text { Roughness }\end{array}$} & \multicolumn{3}{|c|}{$\begin{array}{c}\text { Group A } \\
N(\%)\end{array}$} & \multicolumn{3}{|c|}{$\begin{array}{c}\text { Group B } \\
\text { N ( } \%)\end{array}$} & \multicolumn{3}{|c|}{$\begin{array}{c}\text { Total } \\
\text { N (\%) }\end{array}$} \\
\hline & WL & $\mathbf{L}$ & Acid & $\mathbf{W L}$ & $\mathbf{L}$ & Acid & WL & $\mathbf{L}$ & Acid \\
\hline Decrease & $4(66.7)$ & $5(83.3)$ & $1(16.7)$ & $5(83.3)$ & $6(100)$ & $2(33.3)$ & $9(75)$ & $11(91.7)$ & $3(25)$ \\
\hline No change & $2(33.3)$ & $1(16.7)$ & $2(33.3)$ & $1(16.7)$ & 0 & $3(50)$ & $3(25)$ & $1(8.3)$ & $5(41.7)$ \\
\hline Increase & 0 & 0 & $3(50)$ & 0 & 0 & 1 (16.7) & 0 & 0 & $4(33.3)$ \\
\hline Total & $6(100)$ & $6(100)$ & $6(100)$ & $6(100)$ & $6(100)$ & $6(100)$ & 12 (100) & 12 (100) & $12(100)$ \\
\hline
\end{tabular}

Abbreviations: WL, laser with water irrigation; L, laser without water irrigation.

changing surface roughness was significant $(P=0.05)$ but the difference between $\mathrm{L}$ and WL $(P=0.3)$ or citric acid and WL $(P=0.1)$ were not statistically meaningful.

The difference between the 2 groups $A$ and $B$ in terms of changing the surface roughness by the three techniques was statistically significant $(P=0.002)$. The differences between citric acid and $\mathrm{L}(P=0.01)$, and citric acid and WL $(P=0.01)$ were significant in this respect but $\mathrm{L}$ and $\mathrm{WL}$ were not significantly different in this regard $(P=0.31)$ (Table 2).

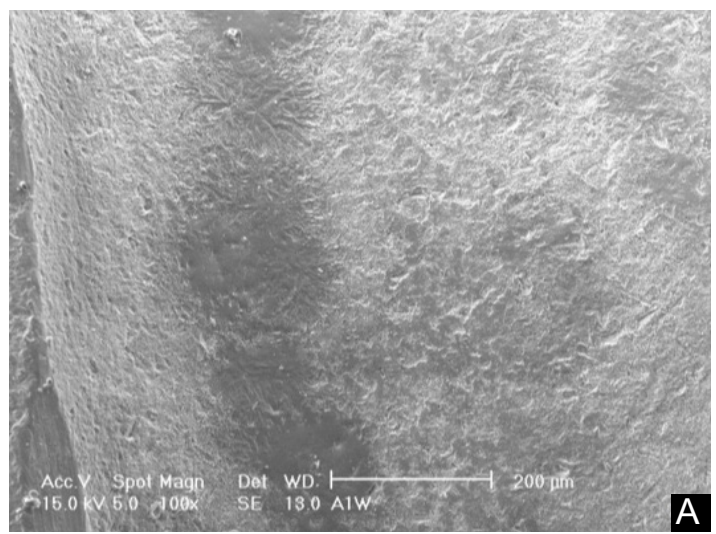

\section{Aluminum}

In group $\mathrm{A}$, the greatest Aluminum content was observed after treatment with citric acid, while the lowest value was observed in the $\mathrm{L}$ group. In group $\mathrm{B}$, the greatest $\mathrm{Al}$ content was observed after treatment with citric acid; while the lowest value was observed in the WL group. The difference in this regard between the three techniques was not significant neither in the group $A$ nor in the group $\mathrm{B}(P=0.1$ for group $\mathrm{A}$ and $P=0.5$ for group $\mathrm{B})$. The difference between the 2 groups of $A$ and $B$ was not

Figure 1. SEM Analysis (×100) Laser (A) Versus Super Saturated Citric Acid (B) in Debridement of Contaminated Implant Surface. 
significant either $(P=0.6)$.

\section{Phosphorous}

In groups $\mathrm{A}$ and $\mathrm{B}$, the highest $\mathrm{P}$ content was noted in the citric acid group; while the lowest was in the LW group. The difference between the 3 techniques in this regard was statistically significant in both groups $(P=0.009$ for group $\mathrm{A}$ and $P=0.03$ for group $\mathrm{B}$ ). In group $\mathrm{A}$, the differences between citric acid and $\mathrm{L}(P=0.02)$ and also between citric acid and WL were statistically significant in this respect $(P=0.02)$. The difference between $\mathrm{L}$ and WL was not statistically significant $(P=0.4)$.

In group $B$ the difference between citric acid and $W L$ was significant $(P=0.02)$; while the differences between citric acid and $\mathrm{L}(P=0.1)$ and also $\mathrm{L}$ and $\mathrm{WL}(P=0.2)$ were not significant.

The difference between groups A and B was statistically significant in this regard $(P=0.001)$.

\section{Titanium}

In groups A and B, the lowest Ti content was observed in the citric acid group. The differences between the three techniques were statistically significant in both $\mathrm{A}$ and $\mathrm{B}$ groups $(P=0.009$, and $P=0.006$, respectively). In group A, the differences between citric acid and $\mathrm{L}(P=0.02)$ and also between citric acid and WL (0.02) were statistically significant, but the difference between $\mathrm{L}$ and WL was not statistically significant in this aspect $(P=0.4)$.

In group $\mathrm{B}$, the differences between citric acid and WL $(P=0.02)$ and also between citric acid and $\mathrm{L}(P=0.02)$ were significant, but the difference between $\mathrm{L}$ and $\mathrm{WL}$ $(P=0.3)$ was not statistically meaningful. The difference between $\mathrm{A}$ and $\mathrm{B}$ groups was significant as well $(P=0.001)$.

\section{Calcium}

In group A, the greatest Calcium content was observed in the citric acid group, while the lowest rate was observed in the WL group. The difference between the three techniques was not significant in group $\mathrm{A}(P=0.1)$ or $\mathrm{B}$ $(P=0.7)$. The difference between groups $\mathrm{A}$ and $\mathrm{B}$ was not statistically significant in this regard $(P=0.1)$ (Table 3$)$.

\section{Discussion}

In this in vitro study, we evaluated the effect of citric acid and Er,Cr:YSGG laser on 12 failed implants in terms of calculus removal and surface roughness. We found that laser (WL, L) application was more effective than citric acid for calculus removal. Using WL technique, acceptable calculus removal was achieved in $25 \%$, extensive calculus removal in $33 \%$ and complete removal in $41.7 \%$ of the cases. Extensive calculus removal was achieved in $75 \%$ of implants using $\mathrm{L}$ technique, while in implants treated with citric acid complete removal did not occur in any case.

Similar to our investigation, in a study, Miller compared the efficacy of Er, Cr: YSGG laser with citric acid $40 \%$ for debriding contaminated implant surfaces and reported results in line with those of ours. In Miller's study, the implants were divided into 2 groups of titanium plasma sprayed (TPS) group and hydroxyapatite (HA) group. The 2 groups were further divided based on the surface treatment into 3 groups of control (untreated), 40\% citric acid washed and laser treated. Laser treatment was done for TPS and HA groups using Er,Cr:YSGG (Biolase technology, USA) laser with a $600 \mu \mathrm{m}$ tip with a power setting of $6 \mathrm{~W}$ followed by an air pressure setting of 100 and water spray at 32 for 3 minutes. Citric acid $40 \%$ at $\mathrm{pH}=1$ was applied for three minutes followed by one minute of sterile rinse. The results for TPS group showed that after surface treatment there was a decrease in organic smear layer when YSGG laser was used as compared to the control group, whereas citric acid treatment failed to remove the organic smear layer. Surface analysis of HA group revealed that the YSGG laser removed the organic smear layer completely whereas citric acid showed incomplete coating removal, loss of crystalline of the remaining bioactive coating and no loss of organic smear layer. Furthermore, Er,Cr:YSGG laser showed superior debridement properties when compared to $40 \%$ citric acid used on TPS and HA implants. ${ }^{13}$

Conversely, Misch, in his study in contrast to ours and Miller's findings, recommended a treatment for failing implants using $40 \%$ citric acid. ${ }^{14}$

In our study, citric acid significantly increased the surface roughness compared to laser (WL and L). It seems that the Er,Cr:YSGG irradiation did not damage the implant surface. Similar to our survey, Schwarz et al in 2006 indicated that Er,Cr:YSGG irradiation with $2.5 \mathrm{~W}$

Table 3. Comparison of AI, P, Ca and Ti Released by 3 Techniques in 2 Groups

\begin{tabular}{|c|c|c|c|c|c|c|c|c|c|}
\hline \multirow{2}{*}{$\begin{array}{l}\text { Treatment } \\
\text { Methods }\end{array}$} & \multicolumn{3}{|c|}{$\begin{array}{c}\text { Group A } \\
n=6\end{array}$} & \multicolumn{3}{|c|}{$\begin{array}{c}\text { Group B } \\
n=6\end{array}$} & \multicolumn{3}{|c|}{$\begin{array}{c}\text { Total } \\
\mathrm{n}=12\end{array}$} \\
\hline & WL & $\mathbf{L}$ & $\begin{array}{l}\text { Citric } \\
\text { Acid }\end{array}$ & WL & $\mathbf{L}$ & $\begin{array}{l}\text { Citric } \\
\text { Acid }\end{array}$ & WL & $\mathbf{L}$ & $\begin{array}{l}\text { Citric } \\
\text { Acid }\end{array}$ \\
\hline $\mathrm{Al}$ & $2.37 \pm 4.2$ & $2.11 \pm 3.4$ & $3.76 \pm 8.3$ & $2.42 \pm 4.4$ & $2.46 \pm 4.3$ & $3.43 \pm 6.7$ & $2.39 \pm 4.1$ & $2.28 \pm 3.7$ & $3.6 \pm 7.2$ \\
\hline $\mathrm{P}$ & $2.28 \pm 0.9$ & $2.47 \pm 0.7$ & $5.5 \pm 1.9$ & $2.3 \pm 0.9$ & $2.7 \pm 0.9$ & $5.4 \pm 2.8$ & $2.3 \pm 0.8$ & $2.5 \pm 0.8$ & $5.4 \pm 2.3$ \\
\hline $\mathrm{Ca}$ & $0.32 \pm 0.3$ & $0.4 \pm 0.3$ & $0.8 \pm 0.5$ & $0.4 \pm 0.5$ & $0.3 \pm 0.3$ & $0.4 \pm 0.3$ & $0.4 \pm 43$ & $0.4 \pm 0.3$ & $0.6 \pm 0.4$ \\
\hline $\mathrm{Ti}$ & $93.1 \pm 4.6$ & $92.6 \pm 4.2$ & $83.2 \pm 7.4$ & $93.4 \pm 5.8$ & $93.1 \pm 4.5$ & $83.9 \pm 5.7$ & $93.2 \pm 5.0$ & $92.8 \pm 4.2$ & $83.5 \pm 6.3$ \\
\hline
\end{tabular}


power did not damage the surface of titanium implants; moreover, the authors divulged that this laser wavelength significantly removed the biofilm plaque. Additionally, they showed that laser application was very effective in bacterial decontamination and had advantages in the reduction of bleeding, swelling, and pain. ${ }^{15}$

During mechanical debridement, any metal to metal contact has the potential to damage the implant surface and then the roughened or scratched implant surface allows for increased bacterial colonization leading to increased risk of destruction in the supporting alveolar bone and implant failure. ${ }^{16}$ Matarasso et al showed that ultrasonic metal tip scalers caused pitting, marked morphological alterations and subsequent bacterial colonization on the surface of titanium implants. ${ }^{17}$ On the other hand, failure to complete surface detoxification or alteration of implant surfaces can compromise the boneimplant contact leading to reduced treatment success. Thus, bacterial decontamination without damaging the implant surface is a key point in the treatment of periimplantitis. ${ }^{7,18,19}$

$\mathrm{Al}, \mathrm{P}$ and $\mathrm{Ca}$ content was greater in the citric acid group, while $\mathrm{Ti}$ content was higher in the laser group. However, the difference in this regard was not statistically significant.

Matsuyama et al in their report indicated that the Er:YAG laser effectively removed the calculus and plaque on contaminated abutments without damaging the titanium surface or causing major temperature rise. ${ }^{20}$

One limitation of the present study was the relatively small sample size. Also, we did not evaluate or compare the results at different power and frequency settings of Er,Cr:YSGG laser. Therefore, further investigations with larger sample size are required to assess the effect of different power and frequency settings of Er,Cr:YSGG laser on calculus removal, surface roughness, and periimplant disease.

Beside the Er,Cr:YSGG, researchers have discussed the efficacy of other wavelengths of laser on periimplantitis. ${ }^{7,21}$ Block et al stated that an Nd: YAG laser on TPS and HA coated implant surfaces resulted in unwanted surface alterations and incomplete decontamination. ${ }^{22}$ Diode laser such as 810 or $980 \mathrm{~nm}$ has been shown to provide bacteria reduction without damaging implant surfaces. ${ }^{7,23,24} \mathrm{Co}_{2}$ and Er; YAG laser ensures a reliable decontamination of implants without altering surface morphology. ${ }^{25,26}$ Furthermore; Recently, photodynamic therapy using a nontoxic chemical agent (photosensitizer) in combination with low power light has been proposed as a novel treatment modality in peri-implantitis. ${ }^{27}$

Temperature changes at the implant-bone contact should be carefully considered during laser application. Temperature rise beyond a $10^{\circ} \mathrm{C}$ threshold above body temperature results in bone destruction, leading to coagulation and denaturation of collagen and bone proteins and to impairment of osteoneogenesis. ${ }^{28-30}$
Geminiani et al declared that the irradiation of sandblasted and acid-etched implant surfaces with diode lasers (810 and $980 \mathrm{~nm}$ ) at $2 \mathrm{~W}$ in continuous mode may produce a temperature rise above the critical threshold $\left(10^{\circ} \mathrm{C}\right)$ after only 10 seconds. ${ }^{31}$ Park et al stated that NdYAG laser irradiation on the titanium surface led to damage to the micromachined surface and coating of implant surfaces as well as an undesirable melting effect; while CO2 laser had minimum alteration on the implant surface with minor temperature increase. ${ }^{32}$ Leja et al determined the effect of diode lasers $(810 / 980 \mathrm{~nm})$, carbon dioxide, and Er:YAG lasers with 4 different setting on the implant surface temperature and concluded that only diode lasers with a power of $1 \mathrm{~W}$ in pulse mode did not increase the implant temperature above the critical temperature threshold..$^{33}$ Kreisler et al indicated that Nd:YAG and Ho:YAG lasers are not proper choices for use in detoxification of implant surfaces, regardless of the power output; Er:YAG and CO2 laser irradiations can be the suitable approaches with controlled power output to avoid surface alterations..$^{21,34}$ Stubinger et al stated that Er:YAG setting for implant surface irradiation should be limited up to 300 or 500 $\mathrm{mJ} / 10 \mathrm{~Hz}^{24}$ and it seems that ErCr:YSGG laser with refrigeration does not generate thermal increments at the apical surface. ${ }^{35}$

In conclusion, the Er,Cr:YSGG laser was more effective in calculus removal and caused less surface roughness compared to citric acid application and considering the limitations of this study, this kind of laser application may be used for the treatment of peri-implantitis. More studies, especially animal and clinical trials are needed in order to provide evidence for the use of this laser application in the treatment of peri-implant diseases.

\section{Ethical Considerations}

This article does not contain any studies with human or animal subjects performed by any of the authors.

\section{Conflict of Interests}

The authors declare no conflict of interest.

\section{Acknowledgments}

We would like to extend sincerer thanks from all support and cooperations of Dr. Behzah Hoshmand in this project.

\section{References}

1. Todisco M, Trisi P. Histomorphometric evaluation of six dental implant surfaces after early loading in augmented human sinuses. J Oral Implantol. 2006;32(4):153-166. doi: $10.1563 / 812.1$

2. Lopez-Marcos JF. Aetiology, classification and pathogenesis of pulp and periapical disease. Med Oral Patol Oral Cir Bucal. 2004;9 Suppl:58-62; 52-57.

3. Nair PN. Pathogenesis of apical periodontitis and the causes of endodontic failures. Crit Rev Oral Biol Med. 2004;15(6):348-381.

4. Berglundh T, Lindhe J, Ericsson I, Marinello CP, 
Liljenberg B, Thomsen P. The soft tissue barrier at implants and teeth. Clin Oral Implants Res. 1991;2(2):8190.

5. Deppe H, Horch HH, Neff A. Conventional versus $\mathrm{CO} 2$ laser-assisted treatment of peri-implant defects with the concomitant use of pure-phase beta-tricalcium phosphate: a 5-year clinical report. Int J Oral Maxillofac Implants. 2007;22(1):79-86.

6. Shetty B, Dinesh A, Seshan H. Comparitive effects of tetracyclines and citric acid on dentin root surface of periodontally involved human teeth: A scanning electron microscope study. J Indian Soc Periodontol. 2008;12(1):815. doi:10.4103/0972-124X.44090

7. Goncalves F, Zanetti AL, Zanetti RV, et al. Effectiveness of 980-mm diode and 1064-nm extra-long-pulse neodymium-doped yttrium aluminum garnet lasers in implant disinfection. Photomed Laser Surg. 2010;28(2):273-280. doi:10.1089/pho.2009.2496

8. Lee JH, Kwon YH, Herr Y, Shin SI, Chung JH. Effect of erbium-doped: yttrium, aluminium and garnet laser irradiation on the surface microstructure and roughness of sand-blasted, large grit, acid-etched implants. J Periodontal Implant Sci. 2011;41(3):135-142. doi:10.5051/ jpis.2011.41.3.135

9. Wang X, Ishizaki NT, Suzuki N, Kimura Y, Matsumoto K. Morphological changes of bovine mandibular bone irradiated by Er,Cr:YSGG laser: an in vitro study. J Clin Laser Med Surg. 2002;20(5):245-250. doi:10.1089/10445470260420740

10. Ting CC, Fukuda M, Watanabe T, Aoki T, Sanaoka A, Noguchi T. Effects of Er,Cr:YSGG laser irradiation on the root surface: morphologic analysis and efficiency of calculus removal. J Periodontol. 2007;78(11):2156-2164. doi:10.1902/jop.2007.070160

11. Gordon W, Atabakhsh VA, Meza F, et al. The antimicrobial efficacy of the erbium, chromium:yttrium-scandiumgallium-garnet laser with radial emitting tips on root canal dentin walls infected with Enterococcus faecalis. $J$ Am Dent Assoc. 2007;138(7):992-1002.

12. Crespi R, Romanos GE, Cassinelli C, Gherlone E. Effects of Er:YAG laser and ultrasonic treatment on fibroblast attachment to root surfaces: an in vitro study. J Periodontol. 2006;77(7):1217-1222. doi:10.1902/ jop. 2006.050416

13. Miller RJ. Treatment of the contaminated implant surface using the Er,Cr:YSGG laser. Implant Dent. 2004;13(2):165-170.

14. Misch C. Contemporary Implant Dentistry. St.Louis: Mosby; 2008:1077-1081.

15. Schwarz F, Sculean A, Rothamel D, Schwenzer K, Georg T, Becker J. Clinical evaluation of an Er:YAG laser for nonsurgical treatment of peri-implantitis: a pilot study. Clin Oral Implants Res. 2005;16(1):44-52. doi:10.1111/ j.1600-0501.2004.01051.x

16. Mann M, Parmar D, Walmsley AD, Lea SC. Effect of plastic-covered ultrasonic scalers on titanium implant surfaces. Clin Oral Implants Res. 2012;23(1):76-82. doi:10.1111/j.1600-0501.2011.02186.x

17. Matarasso S, Quaremba G, Coraggio F, Vaia E, Cafiero C, Lang NP. Maintenance of implants: an in vitro study of titanium implant surface modifications subsequent to the application of different prophylaxis procedures. Clin Oral Implants Res. 1996;7(1):64-72.

18. Renvert S, Lindahl C, Roos Jansaker AM, Persson GR. Treatment of peri-implantitis using an Er:YAG laser or an air-abrasive device: a randomized clinical trial. J Clin Periodontol. 2011;38(1):65-73.

19. Lindhe J, Meyle J. Peri-implant diseases: Consensus Report of the Sixth European Workshop on Periodontology. $J$ Clin Periodontol. 2008;35(8 Suppl):282-285. doi:10.1111/ j.1600-051X.2008.01283.x

20. Matsuyama T, Aoki A, Oda S, Yoneyama T, Ishikawa I. Effects of the Er:YAG laser irradiation on titanium implant materials and contaminated implant abutment surfaces. J Clin Laser Med Surg. 2003;21(1):7-17. doi:10.1089/10445470360516680

21. Kreisler M, Gotz H, Duschner H. Effect of Nd:YAG, Ho:YAG, Er:YAG, CO2, and GaAIAs laser irradiation on surface properties of endosseous dental implants. Int $J$ Oral Maxillofac Implants. 2002;17(2):202-211.

22. Block CM, Mayo JA, Evans GH. Effects of the Nd:YAG dental laser on plasma-sprayed and hydroxyapatitecoated titanium dental implants: surface alteration and attempted sterilization. Int J Oral Maxillofac Implants. 1992;7(4):441-449.

23. Castro GL, Gallas M, Nunez IR, Borrajo JL, Alvarez JC, Varela LG. Scanning electron microscopic analysis of diode laser-treated titanium implant surfaces. Photomed Laser Surg. 2007;25(2):124-128. doi:10.1089/ pho.2006.1086

24. Stubinger S, Etter C, Miskiewicz M, et al. Surface alterations of polished and sandblasted and acid-etched titanium implants after Er:YAG, carbon dioxide, and diode laser irradiation. Int J Oral Maxillofac Implants. 2010;25(1):104-111.

25. Kreisler M, Kohnen W, Christoffers AB, et al. In vitro evaluation of the biocompatibility of contaminated implant surfaces treated with an Er: YAG laser and an air powder system. Clin Oral Implants Res. 2005;16(1):36-43. doi:10.1111/j.1600-0501.2004.01056.x

26. Romanos GE, Nentwig GH. Regenerative therapy of deep peri-implant infrabony defects after CO2 laser implant surface decontamination. Int $J$ Periodontics Restorative Dent. 2008;28(3):245-255.

27. Takasaki AA, Aoki A, Mizutani K, et al. Application of antimicrobial photodynamic therapy in periodontal and peri-implant diseases. Periodontol 2000. 2009;51:109140. doi:10.1111/j.1600-0757.2009.00302.x

28. Eriksson AR, Albrektsson T. Temperature threshold levels for heat-induced bone tissue injury: a vital-microscopic study in the rabbit. J Prosthet Dent. 1983;50(1):101-107.

29. Eriksson RA, Albrektsson T. The effect of heat on bone regeneration: an experimental study in the rabbit using the bone growth chamber. J Oral Maxillofac Surg. 1984;42(11):705-711.

30. Lambrecht JT, Nyffeler T, Linder M. Thermal conduction of titanium implants under CO2 laser irradiation in vitro. Ann Maxillofac Surg. 2012;2(1):12-16. doi:10.4103/22310746.95310

31. Geminiani A, Caton JG, Romanos GE. Temperature 
change during non-contact diode laser irradiation of implant surfaces. Lasers Med Sci. 2012;27(2):339-342. doi:10.1007/s10103-010-0876-8

32. Park CY, Kim SG, Kim MD, Eom TG, Yoon JH, Ahn SG. Surface properties of endosseous dental implants after NdYAG and $\mathrm{CO} 2$ laser treatment at various energies. J Oral Maxillofac Surg. 2005;63(10):1522-1527. doi:10.1016/j.joms.2005.06.015

33. Leja C, Geminiani A, Caton J, Romanos GE. Thermodynamic effects of laser irradiation of implants placed in bone: an in vitro study. Lasers Med Sci. 2012. doi:10.1007/s10103-012-1215-z

34. Kreisler M, Al Haj H, Gotz H, Duschner H, d'Hoedt B. Effect of simulated $\mathrm{CO} 2$ and GaAlAs laser surface decontamination on temperature changes in Ti-plasma sprayed dental implants. Lasers Surg Med. 2002;30(3):233239.

35. Gómez-Santos L A-DJ, Sierra-Rebolledo A, Gay-Escoda C. Thermal increment due to ErCr:YSGG and CO2 laser irradiation of different implant surfaces. A pilot study. Med Oral Patol Oral Cir Bucal. 2010 Sep 1;15(5):e782787. 